\title{
Öğretmen Adaylarının Hedefi Gerçekleştirme Stillerinin Belirlenmesi
}

\author{
Determining Prospective Teachers'Styles of Goal Accomplishment
}

\begin{abstract}
Şule AKYOL ${ }^{*}$ Hilmi DEMİRKAYA**

Özet: Hedefe yönelme, birey ve örgütlerin temel amaçlarına ilişkin eylemlerini açıklar. Bu araştırma, öğretmen adaylarının hedefi gerçekleştirme stillerinin özelliklerini tanımlamaya yönelik olarak gerçekleştirilmiştir. Ayrıca, öğretmen adaylarının hedefi gerçekleştirme stillerinin cinsiyete ve bölümlere göre farklılaşıp farklılaşmadığı da belirlenmiştir. Araştırmada, Atman (1986) tarafından geliştirilen "Amaca Yönelme İndeksi” kullanılmıştır. Ölçek, öğrencilerin bireysel hedefi gerçekleştirme stili profilini oluşturan kişisel rapor envanteri özelliği taşıyan 96 maddeden meydana gelmektedir ve Mehmet Akif Ersoy Üniversitesi Eğitim Fakültesi'nde öğrenim gören 167 öğretmen adayına uygulanmıştır. Verilerin analizinde frekans, yüzde, $t$-testi ve ANOVA kullanılmıştır. T-testi sonucuna göre kızlar ve erkekler arasında anketin alt boyutlarına ilişkin anlamlı bir fark bulunamamıştır. ANOVA sonuçları ise; ölçeğin hareket boyutuna ilişkin resim eğitimi öğretmenliği bölümü öğrencileri ile Türkçe eğitimi öğretmenliği bölümü öğrencileri arasında anlamlı bir fark olduğunu göstermektedir. Benzer şekilde ölçeğin hareket boyutuna ilişkin resim eğitimi öğretmenliği bölümü öğrencileri ile matematik öğretmenliği öğrencileri arasında da anlamlı bir fark bulunmuştur. Ölçeğin diğer boyutlarına ilişkin olarak öğrencilerin öğrenim gördükleri bölümler arasında anlamlı bir farka rastlanılamamıştır.
\end{abstract}

Anahtar Sözcükler: Amaca Yönelme İndeksi (AYİ), Hedefi Gerçekleştirme Stili, Öğretmen Adayı, Çaba

Abstract: The term goal orientation describes the actions of people and organizations in regard to their primary aims. The aim of this study was to investigate prospective teachers' goal accomplishment style characteristics. Further, if the prospective teachers' goal accomplishment style changed or was affected by gender and area of specialization. In this study the goal orientation index, developed by Atman was used. The data was a total of 96 self-report inventory, recording the prospective teachers' individual goal accomplishment style profile. The study participants were 167 prospective teachers at the Mehmet Akif Ersoy University Faculty of Education. Frequency, percentage, t-test and ANOVA were used in the analysis of data obtained from this research. According to the t-test scores there was no significant difference between subdimensions of the instrument. ANOVA analyses were implemented and the results indicated that there were significant differences between prospective art teachers and prospective Turkish teachers. Also, there were significant differences between prospective art teachers and prospective mathematics teachers. There was no significant differences amongst the other majors.

Keywords: Goal Orientation Index (GOI), Goal Accomplishment Style, Prospective Teachers, Conation

Kant'tan bu yana akıl, geleneksel olarak üç zihinsel fonksiyona ayrılmaktadır: Biliş, çaba ve duygu. Alman Felsefesinde ve Psikolojisinde çaba (conation), bireyin istemli katılımı olarak bilinmektedir. English, \& English (1958, 104) tarafından yapılan geleneksel tanım ise şöyledir: "Çaba, başka bir şeyi geliştirmeye yönelik ĕ̌ilimi olan (istekli olmak) zihinsel süreç ya da

\footnotetext{
* Arş. Gör., Mehmet Akif Ersoy Üniversitesi, Eğitim Fakültesi, Eğitim Bilimleri Bölümü, akyolsule@gmail.com

** Doç. Dr., Akdeniz Üniversitesi, Eğitim Fakültesi, İlköğretim Bölümü, hdemirkaya@akdeniz.edu.tr
} 
davranış özellikleridir. Organizmanın iç karmaşıllı̆̆ ya da doğuştan getirdiği özelliği olup yaklaşık olarak homeostazın (dinamik öz-düzenleme) zıt anlamlısıdır. Eyleme dönük bilinçli bir eğilim bilinçli bir gayrettir." Atman'a $(1986,3)$ göre çaba; “istemli yönlendirilmiş enerji, yani hem yön hem de büyüklüğe sahip bireysel enerjidir." Bazı çaba tanımları da şu şekildedir: "Geleneksel olarak biliş ve duyuştan ayrılmış olan, insanların amaç ve arayışlarını içeren ruhsal yaşam (gizli güç) özellikleridir" (Good, 1973). "Eylem ya da değişime doğru yönlendirilmiş içtepi, arzu, istem ve gayreti içeren zihinsel süreçlerdir" (American Heritage Dictionary of the English Language, 1992).

Bir birey çaba gösterdiği zaman, genellikle onu soyut düzeyde bırakmayacak, bir amaca doğru çaba sarf edecektir (Atman, 1982). Bireysel üretkenlik fenomeninin ileri düzeyde işlemselliği için Atman, “Çaba Döngüsü”nü geliştirmiştir. Çaba Döngüsü (Conation Cycle) başarı güdüsü literatüründen türetilen bir hedef belirleme, problem çözme ve karar verme modelidir. McClelland, et. alii (1975) başarı güdüsünü, üstün standartların uygulanabildiği herhangi bir ortamda başarı için çabalamaya yönelik oldukça istikrarlı bir düzen şeklinde kavramsallaştırmışlardır.

Atman (1982), çabanın dört zihinsel alan olarak düşünülmesi gerektiğini ileri sürmüştür. Dört ayrı alan bilişsel-bilgi, duyuşsal-değerler, çabasal-gayret gösterme ve psiko-motor-yapma (hassas motor hareketi ya da kaba motor koordinasyonu) olarak ifade edilmiştir. Çabasal arayış etkinliğinin diğer zihinsel alanlardan ayrılması, bir bireyin kendi yönlendirmesi ile ilişkili davranışının daha iyi yönetim için gerekli basamağını belirler. Çaba gösterme (striving) her zaman amaç yönelimlidir ve eylem yoluyla açılkanabilir. Atman (1982), amaç yönelimli davranış geliştirmede kullanılabilecek bir ardışıklı adımlar dizisi tanımlamış ve bunu "çaba döngüsü" olarak adlandırmıştır. Çaba döngüsü dört aşamada değerlendirilmiştir. Bu aşamalar amaca yönelik 12 alt kategoriden meydana gelmektedir. Birinci aşama; keşfetme (exploration); ikinci aşama; planlama (commitment); üçüncü aşama; uygulama (administration) ve dördüncü aşama; çözüm (denouement). Bu dört aşama (phases) ve 12 alt kategori aşağıda verilmiştir:

Keşfetme 1. Bir ihtiyaç, problem, zorluk veya firsatı fark etme (plan).

2. Hedef belirleme (plan).

Planlama 3. Alternatifleri değerlendirme (düşünüp taşınma).

4. Risk hesaplama (düşünüp taşınma).

5. Strateji seçme (hareket).

6. Gözünde canlandırma (düşünüp taşınma).

Uygulama 7. Düzenleme (plan).

8. Gerçekleştirme (hareket).

9. İlerleme (hareket).

10. Sona erdirme (hareket).

Çözüm 11. Evet! Sonunda! Değerlendirme (düşünüp taşınma).

12. Gaye, uzun vadeli hedefler edinme (plan).

Döngünün çeşitli adımlarında birey; planlar, harekete geçer, düşünüp taşınır ve kendi isteminin niteliklerinden yararlanır (Assagioli, 1973).

Mueller (1988), çaba döngüsünün dört aşamasını ve on iki adımını özetlemiştir. Keşfetme (exploration) aşaması iki adımdan meydana gelmektedir: Birinci adım; bir ihtiyaç, problem, güçlük veya fırsatı fark etme ve ikinci adım; hedef belirlemedir. Çaba döngüsü, öncelikle tespit edilmiş bir amaçla başlar. Hedefe ulaşmak için yapılacak ihtiyaçlar her ne olursa olsun tanımlanır (bu birinci adımdır). Bundan başka, hedefe ulaşma yönünde bir amaç belirlenir (bu 
ikinci adımdır). Görev için sorumluluğu kabul etme, özellikle bu aşamada riske girmeyi göze almakla ilişkilidir (Atman, 1982).

Planlama aşaması 3-6. adımlardan meydana gelir: Üçüncü adım, alternatifleri değerlendirme; dördüncü adım, risk hesaplama ve başarı olasılıkları; beşinci adım, strateji seçme ve altıncı adım, gözünde canlandırma. Denekler, amaca ulaşmak için bütün olası yolları göz önünde bulundurur (bu üçüncü adımdır) ve daha sonra olası alternatiflerin her birinde başarı ya da başarısızlık olasılıklarını, risk düzeyini analiz eder (bu dördüncü adımdır). Her bir alternatifin bütün olumlu ve olumsuz yönlerini göz önünde bulundurduktan sonra ve her biriyle ilişkili bireysel güçleri ve zayıflıkları hesaba katarak birey bir strateji seçer. $\mathrm{Bu}$ anda ruhsal enerji (psychical energy) harekete geçirilmiş ve odaklanmıştır (bu beşinci adımdır). Planlama aşaması deneğin yansıtma modu ile aktif mod arasında köprü oluşturduğu yerdir. Ruhsal enerji, gözünde canlandırma yoluyla harekete geçmeye başlar (bu altıncı adımdır). Altıncı adımda yüksek puan alan bir birey, hedefe ulaşıldığı zaman işlerin nasıl gideceğini gözünde canlandırabilen, planlanan etkinliğin zihinsel provasını yapabilen ve hedef başarıldığı zaman hissedeceği başarı ve haz duygularını hayal edebilen kişidir (Atman, 1986).

Uygulama aşaması, 7-10. adımlardan meydana gelir: Yedinci adım, düzenleme; sekizinci adım, gerçekleştirme; dokuzuncu adım, ilerleme ve onuncu adım, sona erdirme. Ruhsal enerji, zihinsel gözünde canlandırmadan somut gerçekleștirmeye doğru hareket eder. Düzenleme, insanlar, kaynaklar, bilgi, olaylar ve onların ilişkileri ile bir zaman envanteri oluşturur (bu yedinci adımdır). Denek, proje çalışmasını uygulamaya başlamıştır (bu sekizinci adımdır). Sekizinci kategoride yüksek puan alan bir birey, eylem yönelimli olup bir projenin "yapma" aşamasının içerisindedir. Eylemi gerçekleştirirken meydana gelen çevresel değişikliklere dikkati çeker. Eylemde meydana gelen gelişmelere göre, eğer gerekiyorsa planda da değişiklikler yapabilir (Atman, \& Petlevic, 1990). Verilen görevle ilgilenirken problem üzerine doğrudan odaklanmak, bireye engellere direnerek sabırla ilerleme firsatı tanıyacaktır (bu dokuzuncu adımdır). Engellere karşı direnme, bir görev tamamlayıcı olarak bireyin başarılı olmasını sağlayarak çabasal kapasitesini geliştirir (bu onuncu adımdır). Bu kategoriden yüksek puan alan bir birey projenin son teslim tarihini görmüştür. Yani, bu birey engellerle karşılaştığında onları aşma ve bir defa başladığı bir işi sonuçlandırma konusuna ayrıntılı bir şekilde dikkat ederek başladığı işi tamamlar (Atman, \& Petlevic, 1990). Uygulama aşamasında kullanılan yönetim, bireyin yönetimine katkıda bulunur. Öz-disiplin ve kontrol, planın öz-yönetiminde gereklidir.

Çözüm aşaması (Denouement phase), on birinci adım değerlendirme ve on ikinci adım yeniden gruplama adımlarından meydana gelmektedir. Görev tamamlandığı zaman, işin bütün yönleri değerlendirilir ve eleştirilir (bu onbirinci adımdır). Bu kategoride yüksek puan alan bir birey tamamladığı ve yaptığı bir işi bütün yönleri ile değerlendirmek/eleştirmek için sert ölçütler kullanan birisidir. Son olarak tamamlanmış görev uzun vadeli hedeflerle ilişkili yolda yeniden değerlendirilir (bu onikinci adımdır). "Çözüm aşamasının son adımında iken, birey yansitıcı moddan (reflective mode-yansıtıcı biçim) aktif moda hareket eder. Çözüm aşaması bireyi tekrar yansitıcı moda geri götürür" (Atman, 1982, 82). Dördüncü aşamanın vurgusu, değerlendirme üzerinedir. Bireyler aktif moddan yansıtıcı moda tekrar geri taşınabilir (Atman, 1982).

Çaba çevriminin 12 alt kategorisi 3 ana kategoride toplanmıştır: Hareket (eylem), plan ve düşünüp taşınma (yansıtma).

\section{Çaba Çevrimi Ana Kategorileri (Davis, 1995, 35)}

\section{Hareket}

5. Strateji Seçme

8. Gerçekleştirme 
9. İlerleme

10. Sona Erdirme

\section{Plan}

1. Bir ihtiyaç, problem, zorluk veya firsatı fark etme

2. Hedef Belirleme

7. Düzenleme

12. Gaye, uzun vadeli hedefler edinme

\section{Düşünüp Taşınma}

3. Alternatifleri Değerlendirme

4. Risk Hesaplama

6. Gözünde Canlandırma

11. Evet! Sonunda! (Değerlendirme)

\section{Amaç}

Bu çalışmada Mehmet Akif Ersoy Üniversitesi Eğitim Fakültesinde belirlenen bölümlerde öğrenim gören öğretmen adaylarının, "amaca yönelme indeksi" kullanılarak hedefi gerçekleştirme stillerini belirlemek amaçlanmıştır. Araştırmanın alt amacına ilişkin soru cümleleri şunlardır:

1) Belirlenen bölümlerde öğrenim gören öğretmen adaylarının hedefi gerçekleştirme stilleri arasında cinsiyete göre anlamlı bir fark var mıdır?

2) Belirlenen bölümlerde öğrenim gören öğretmen adaylarının hedefi gerçekleştirme stilleri arasında öğrenim gördükleri bölümlere göre anlamlı bir fark var mıdır?

\section{Yöntem}

\section{Araștırmanın Modeli}

$\mathrm{Bu}$ araştırma, öğretmen adaylarının hedefi gerçekleştirme stillerini belirlemeye yönelik, betimsel tarama modelinde nicel bir araştırmadır. Bu araştırmada var olan bir durumu, var olduğu şekliyle betimlemeyi amaçlayan araştırma yaklaşımları "tarama modeli" kullanılmıştır (Karasar, 2009).

\section{Çalışma Grubu}

Araştırmanın çalışma grubunu Mehmet Akif Ersoy Üniversitesi Eğitim Fakültesi, İlköğretim Matematik Öğretmenliği, Fen Bilgisi ve Teknoloji Eğitimi, Türkçe Eğitimi, İngilizce Öğretmenliği, Resim-İș Eğitimi Öğretmenliği bölüm/ana bilim dallarında öğrenim gören 167 öğretmen adayı oluşturmaktadır. Bu çalışmada seçkisiz örnekleme yöntemlerinden "basit seçkisiz örnekleme yöntemi” kullanılmıştır (Büyüköztürk, et. alii, 2008).

Amaca yönelme indeksi uygulanan öğretmen adaylarının cinsiyete göre dağılımı Tablo 1'de verilmiştir:

Tablo 1. Öğretmen Adaylarının Cinsiyete Göre Dağılımı

\begin{tabular}{|l|c|c|}
\hline Cinsiyet & f & \% \\
\hline Kız & 103 & 61,68 \\
\hline Erkek & 64 & 38,32 \\
\hline Toplam & 167 & 100,00 \\
\hline
\end{tabular}


Tablo 1'de görüldüğü gibi öğretmen adaylarının 103 (\%61,68)'ü kızdır, 64 (\%38,32)'ü erkektir. Tablo 2'de öğretmen adaylarının öğrenim gördükleri bölüm/ana bilim dallarına göre dă̆ılımına yer verilmiştir:

Tablo 2. Öğretmen Adaylarının Bölüm/Anabilim Dallarına Göre Dağılımı

\begin{tabular}{|l|c|c|}
\hline Bölüm & f & $\mathbf{\%}$ \\
\hline Resim-İ̧̇ Eğitimi Öğretmenliği & 14 & 8,38 \\
\hline Türkçe Eğitimi & 41 & 24,55 \\
\hline İngilizce Öğretmenliği & 22 & 13,17 \\
\hline İlköğretim Matematik Öğretmenliği & 35 & 20,96 \\
\hline Fen Bilgisi ve Teknoloji Eğitimi & 55 & 32,93 \\
\hline Toplam & 167 & 100 \\
\hline
\end{tabular}

Tablo 2'ye bakıldığında, araştırmaya Resim-İş Eğitimi Öğretmenliği bölümünden 14, Türkçe Eğitimi bölümünden 41, İngilizce Öğretmenliği bölümünden 22, İlköğretim Matematik Öğretmenliği anabilim dalından 35, Fen Bilgisi anabilim dalından ve Teknoloji Eğitimi bölümünden 55 öğretmen adayı katılmıştır.

\section{Ölçme Araçları}

Araştırmada Atman (1986) tarafından geliştirilen, bir öğrencinin 'Amacı Başarma Stili' ile ilgili bilgi veren, 96 maddelik likert tipindeki Amaca Yönelme İndeksi (AYİ) kullanılmıştır. AYİ, Demirkaya (2008) tarafından geçerlik ve güvenirlik işlemleri yapılarak yayımlanmıştır.

\section{İstatistiksel Teknikler}

Verilerin analizinde frekans, yüzde, t-testi ve ANOVA kullanılmıştır.

\section{Bulgular ve Yorum}

\section{1) Alt Probleme İlişkin Bulgular ve Yorum}

Belirlenen bölümlerde öğrenim gören Mehmet Akif Ersoy Üniversitesi Eğitim Fakültesi öğrencilerinin hedefi gerçekleştirme stilleri arasında cinsiyete göre anlamlı bir fark var mıdır?

Üç boyuttan oluşan Amaca Yönelme İndeksi ölçeğinin her bir boyutunun cinsiyete göre t-testi sonuçları Tablo 3'de verilmiştir:

Tablo 3. Amaca Yönelme İndeksi Alt Boyutlarına Ait Cinsiyete Göre t- testi Sonuçları

\begin{tabular}{|c|c|c|c|c|c|c|c|}
\hline $\begin{array}{c}\text { Ölçeğin Alt } \\
\text { Boyutları }\end{array}$ & Cinsiyet & $\mathbf{N}$ & $\overline{\mathrm{X}}$ & Ss & $\mathbf{s d}$ & $\mathbf{t}$ & $\mathbf{p}$ \\
\hline \multirow{2}{*}{ Hareket } & Kadın & 103 & 99.14 & 14.02 & 165 & -.377 & .707 \\
& Erkek & 64 & 100.04 & 16.51 & & & \\
\hline \multirow{2}{*}{ Plan } & Kadın & 103 & 111.68 & 21.03 & 165 & -.340 & .735 \\
& Erkek & 64 & 112.84 & 21.89 & & & \\
\hline \multirow{2}{*}{ Düşünüp Taşınma } & Kadın & 103 & 113.36 & 21.36 & 165 & .413 & .680 \\
& Erkek & 64 & 111.98 & 20.53 & & & \\
\hline
\end{tabular}

Tablo 3'den de görüldüğü gibi kızlar ve erkekler arasında anketin alt boyutlarına ilişkin anlamlı bir fark bulunamamıştır ( $p>.01)$. Bu bulgudan, öğrencilerin cinsiyetlerinin hedefi gerçekleştirme 
stilleri arasında farklılık yaratmadığı sonucuna ulaşılabilir.

\section{2) Alt Probleme İlişkin Bulgular ve Yorum}

Belirlenen bölümlerde öğrenim gören Mehmet Akif Ersoy Üniversitesi Eğitim Fakültesi öğrencilerinin hedefi gerçekleştirme stilleri arasında öğrenim gördükleri bölümlere göre anlamlı bir fark var midır?

Tablo 4. Öğretmen Adaylarının Bölüm/Anabilim Dallarına Göre Hedefe Yönelme İndeksinin Alt Boyutlarına Yönelik Puanlarının Betimsel İstatistikleri

\begin{tabular}{|c|c|c|c|c|}
\hline $\begin{array}{c}\text { Hedefe Yönelme } \\
\text { İndeksinin Alt Boyutları }\end{array}$ & $\begin{array}{c}\text { Bölüm/Anabilim } \\
\text { Dalları }\end{array}$ & $\mathbf{N}$ & $\overline{\mathrm{X}}$ & Ss \\
\hline \multirow{6}{*}{ Hareket } & 1. Resim-İş Öğr. & 14 & 110,64 & 22,39 \\
\hline & 2. Türkçe Öğr. & 41 & 96,00 & 13,98 \\
\hline & 3. İngilizce Öğr. & 22 & 99,41 & 14,13 \\
\hline & 4. Matematik Öğr. & 35 & 95,43 & 11,86 \\
\hline & 5. Fen Bilgisi Öğr. & 55 & 101,87 & 14,18 \\
\hline & Toplam & 167 & 99,49 & 14,99 \\
\hline \multirow{6}{*}{ Plan } & 1. Resim-İş Öğr. & 14 & 118,00 & 26,72 \\
\hline & 2. Türkçe Öğr. & 41 & 106,98 & 21,28 \\
\hline & 3. İngilizce Öğr. & 22 & 110,23 & 19,50 \\
\hline & 4. Matematik Öğgr. & 35 & 112,06 & 22,24 \\
\hline & 5. Fen Bilgisi Öğr. & 55 & 115,29 & 19,70 \\
\hline & Toplam & 167 & 112,13 & 21,31 \\
\hline \multirow{6}{*}{ Düşünüp Taşınma } & 1. Resim-İş Öğr. & 14 & 116,07 & 26,39 \\
\hline & 2. Türkçe Öğr. & 41 & 107,00 & 21,66 \\
\hline & 3. İngilizce Öğr. & 22 & 112,50 & 18,95 \\
\hline & 4. Matematik Öğr. & 35 & 110,49 & 22,07 \\
\hline & 5. Fen Bilgisi Öğr. & 55 & 118,00 & 18,29 \\
\hline & Toplam & 167 & 112,84 & 21,00 \\
\hline
\end{tabular}

Tablo 4 incelendiğinde, hareket boyutunda en yüksek ortalama resim-iş öğretmeni adaylarına $(\bar{X}=110.64)$ aitken, en düşük ortalama matematik öğretmeni adaylarına $(\bar{X}=95.43)$ aittir. Plan boyutunda en yüksek ortalama resim-iş öğretmeni adaylarına $(\bar{X}=118.00)$ aitken, en düşük ortalama matematik öğretmeni adaylarına $(\bar{X}=112.06)$ aittir. Düşünüp Taşınma boyutunda en yüksek ortalama resim-iş öğretmeni adaylarına $(\bar{X}=116.07)$ aitken, en düşük ortalama matematik öğretmeni adaylarına $(\overline{\mathrm{X}}=110.49)$ aittir.

Amaca Yönelme İndeksinin boyutlarına ait öğrencilerin öğrenim gördükleri bölümlere göre ANOVA sonuçları Tablo 5'te verilmiştir: 
Tablo 5. Öğrencilerin Öğrenim Gördükleri Bölümlere Göre ANOVA Sonuçları

\begin{tabular}{|c|c|c|c|c|c|c|c|}
\hline $\begin{array}{l}\text { Hedefe Yönelme } \\
\text { İndeksinin Alt } \\
\text { Boyutları }\end{array}$ & & KT & sd & KO & $\mathbf{F}$ & $\mathbf{p}$ & $\begin{array}{c}\text { Anlamlı } \\
\text { Fark }\end{array}$ \\
\hline \multirow{3}{*}{ Hareket } & Gruplararas1 & 3130,524 & 4 & 782,631 & 3,711 & ,006 & \multirow{3}{*}{$\begin{array}{l}1-2 \\
1-4\end{array}$} \\
\hline & Gruplariçi & 34167,213 & 162 & 210,909 & & & \\
\hline & Toplam & 37297,737 & 166 & & & & \\
\hline \multirow{3}{*}{ Plan } & Gruplararas1 & 2201,031 & 4 & 550,258 & 1,218 & ,305 & \\
\hline & Gruplariçi & 73158,070 & 162 & 451,593 & & & \\
\hline & Toplam & 75359,102 & 166 & & & & \\
\hline \multirow{3}{*}{ Düşünüp Taşınma } & Gruplararası & 3205,463 & 4 & 801,366 & 1,855 &, 121 & \\
\hline & Gruplariçi & 69993,171 & 162 & 432,057 & & & \\
\hline & Toplam & 73198,635 & 166 & & & & \\
\hline
\end{tabular}

Tablo 5'ten "Öğrencilerin Öğrenim Gördükleri Bölümlere Göre ANOVA Sonuçları" incelendiğinde ölçeğin hareket boyutuna ilişkin olarak resim eğitimi öğretmenliği bölümü öğrencileri ile Türkçe eğitimi öğretmenliği bölümü öğrencileri arasında anlamlı bir fark olduğu görülmektedir $\left[\mathrm{F}_{(4-162)}=3,711 ; \mathrm{p}<.01\right]$. Benzer şekilde ölçeğin hareket boyutuna ilişkin resim eğitimi öğretmenliği bölümü öğrencileri ile matematik öğretmenliği öğrencileri arasında da anlamlı bir fark vardır. Alt boyutlar arasındaki farkların hangi gruplar arasında olduğunu bulmak amacıyla yapılan Tukey HSD testinin sonuçlarına göre, öğretmen adaylarının amaca yönelme indeksinden aldıkları puan ortalamaları resim öğretmeni adaylarının $(\overline{\mathrm{X}}=110,64)$, Türkçe öğretmeni adayları $(\bar{X}=96.00)$ ve matematik öğretmeni adaylarına $(\bar{X}=95.43)$ göre daha yüksek olduğu belirlenmiştir. Ölçeğin diğer boyutlarına ilişkin olarak öğrencilerin öğrenim gördükleri bölümler arasında anlamlı bir farka rastlanılamamıştır ( $\mathrm{p}>.01)$.

\section{Sonuç ve Öneriler}

Her bireyin kişisel özellikleri kendine özgüdür, dolayısıyla hedefe ulaşmak için gösterdiği çaba ve izlediği yol da farklılaşmaktadır. Bu araştırmayla Mehmet Akif Ersoy Üniversitesi'nde öğrenim gören öğrencilerin hedefi gerçekleştirme stillerini belirlemek ve karşılaştırmak istenmiştir. Elde edilen bulgulara göre kız ve erkek öğrencilerin hedefi gerçekleştirme stilleri arasında anlamlı bir fark bulunamamıştır, yani öğrencilerin hedefi gerçekleştirme stilleri cinsiyete göre değişmemektedir. Öğrenciler öğrenim gördükleri bölümlere göre karşılaştırıldıklarında ise üç alt boyuttan oluşan ölçeğin hareket alt boyutuna yönelik resim-iş eğitimi öğretmenliği öğrencileri ile Türkçe eğitimi öğrencileri arasında ve resim-iş eğitimi öğretmenliği öğrencileri ile ilköğretim matematik öğretmenliği öğrencileri arasında anlamlı farka rastlanılmıştır. Öğrencilerin hedefi gerçekleştirme stilleri, ölçeğin diğer alt boyutlarına ilişkin öğrenim gördükleri bölümlere göre değişmemektedir. Ölçeğin hareket boyutunda ortaya çıkan bu farklar; resim-iş öğretmenliği öğrencilerinin daha çok uygulamalı dersler işlemelerinden, buna karşılık Türkçe öğrencilerinin dersleri dinleme ve okuma ağırlıklı işlemelerinden ve matematik öğrencilerinin daha soyut işlemelerinden kaynaklanmış olabilir. 
Yeni araştırmalarla farklı bölümlerdeki öğrencilerin hedefi gerçekleştirme stilleriyle farklı meslek grubundaki bireylerin hedefi gerçekleştirme stilleri karşılaştırılabilir.

\section{KAYNAKÇA}

American Heritage Dictionary of English Language, Third Edition. (1992). Boston: Houghton-Mifflin. Assagioli, R. (1973). The Act of will. New York: Viking Press.

Atman, K. S. (1982). "The Conation Phenomenon; A Case for Conation: The Fourth Domain in Education". Unpublished Paper, University of Pittsburgh.

Atman, K. S. (1986). "The Role of Conation (Striving) in The Distance Education Enterprise". American Journal of Distance Education, 1 (1), 14-24.

Atman, K. S., \& Petlevich, J. (1990). "Conative capacity and self-regulation skills of in school suspension students". Paper presented at the American Educational Research Association Annual Meeting, Boston, M. A.

Büyüköztürk, Ş., Kılıç-Çakmak, E., Akgün, Ö. E., Karadeniz, Ş., \& Demirel, F. (2008). Bilimsel Araştırma Yöntemleri. Ankara: Pegem Akademi.

Davis, M. A. (1995). The Interrelationship of Conation, Goal Accomplishment Style and Psychological Type in Distance Learners. Unpublished Doctoral Dissertation. West Virginia University, Morgantown.

Demirkaya, H. (2008). "Using Goal Accomplishment Style to Predict Geography Academic Achievement of Prospective Teachers". Elektronik Sosyal Bilimler Dergisi, 7 (26), 281-305.

English, H. B., \& English, A. C. (1958). A Comprehensive Dictionary of Psychological and Pshchoanalytical Terms: A Guide to Usage. New York: Longmans Green.

Good, C. V. (1973). Dictionary of Education. New York: Mc. Graw-Hill.

Karasar N. (2009). Bilimsel Araştırma Yöntemi. Ankara: Nobel Yayın Dağııım.

McClelland, D. D., Rhinesmith, S., \& Kristeensen, R. (1975). "The Effects of Power Training on Community Action Agencies". Journal of Applied Behavioral Sciences, 11, 92-115.

Mueller, R. J. (1988). A Study of Conative Capacity in Normal and Disturbed at-risk High School Students. Unpublished Doctoral Dissertation. University of Pittsburgh, Pittsburgh. 